\title{
Correction to: Determination of minimum uncut chip thickness under various machining conditions during micro-milling of Ti-6Al-4V
}

\author{
Hamed Rezaei ${ }^{1}$ - Mohammad Hossein Sadeghi ${ }^{1}$ • Erhan Budak ${ }^{2}$ \\ Published online: 14 August 2021 \\ (C) Springer-Verlag London Ltd., part of Springer Nature 2021
}

Correction to: The International Journal of Advanced Manufacturing Technology (2018) 95:1617-1634 https://doi.org/10.1007/s00170-017-1329-3

Figure 12 needs to be replaced with a modified one presented below. The equations are removed from Fig. 12. The manuscript remains unchanged.

Publisher's note Springer Nature remains neutral with regard to jurisdictional claims in published maps and institutional affiliations.

The online version of the original article can be found at https://doi.org/ 10.1007/s00170-017-1329-3

Hamed Rezaei

Hamedrze@gmail.com

1 Department of Mechanical Engineering, TarbiatModares University, Tehran, Iran

2 Faculty of Engineering and Natural Sciences, Sabanci University, Istanbul, Turkey 
(a)

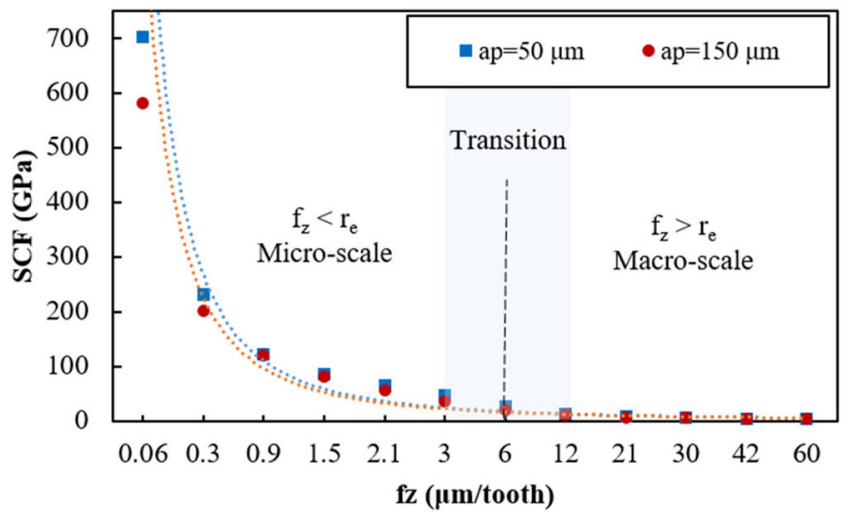

(c)

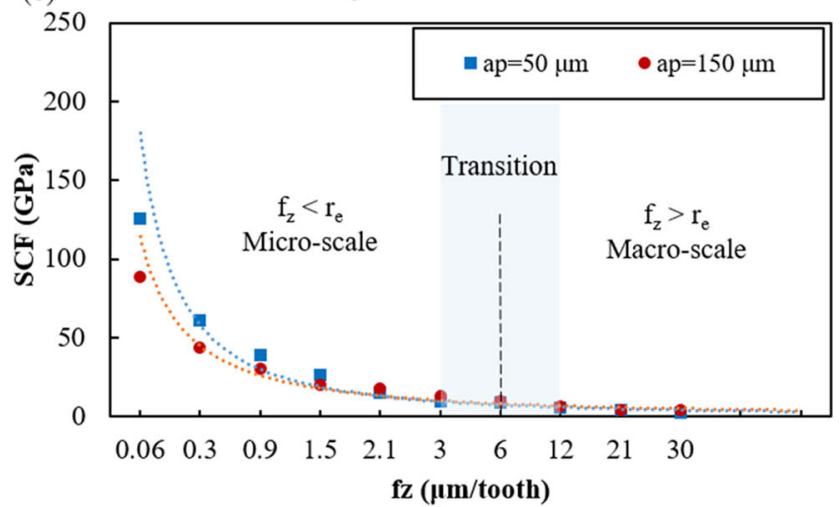

(b)

DRY with $100 \mathrm{~m} / \mathrm{min}$

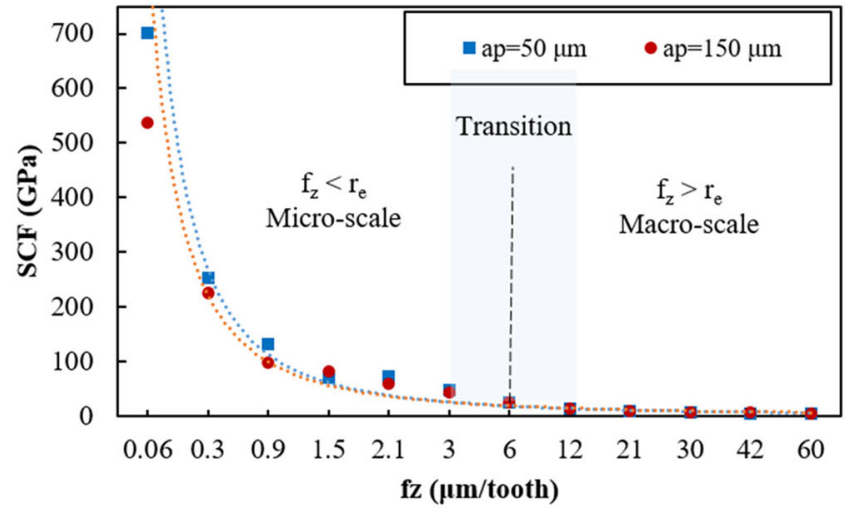

(d)

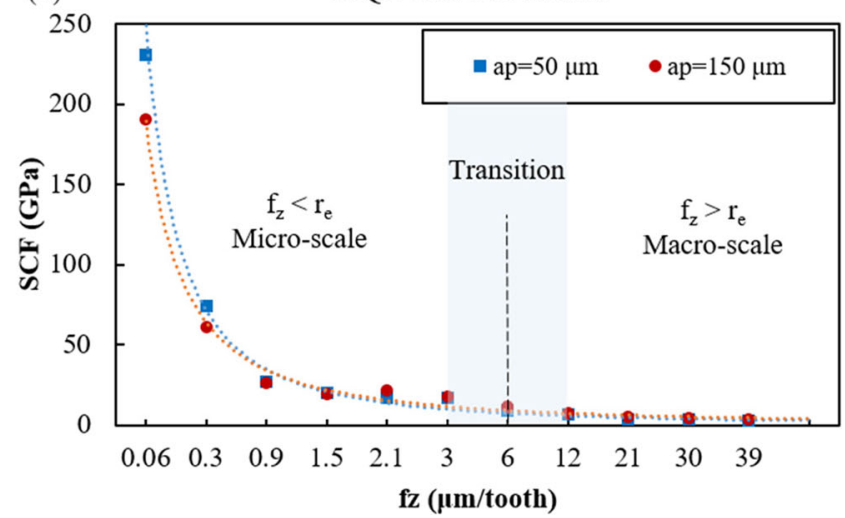

Fig. 12 Dependence of SCF on feed rate at various machining conditions in micro-milling 